\title{
Otredad y marginación: personajes del otro lado en el cine español
} (1999-2012)

\section{Otherness and marginalisation: characters from the other side in Spanish cinema (1999-2012)}

\author{
Inmaculada Gordillo \\ Universidad de Sevilla (US), España \\ ingoal@us.es \\ http://orcid.org/oooo-0002-9090-5166 \\ Sergio Toledo \\ Universidad de Sevilla (Eusa), España \\ sergio.toledo@eusa.es \\ https://orcid.org/0000-0002-3069-1397 \\ María Toscano \\ Universidad de Sevilla (US), España \\ maria.toscano.alonso@gmail.com \\ https://orcid.org/oooo-0002-7263-3400
}

\section{Resumen:}

El cine social español elige evidenciar universos narrativos relacionados con la microhistoria para mostrar una sociedad en evolución a partir de la época de la transición política. El cambio de milenio presenta un panorama que posee muchas diferencias con etapas anteriores por lo que el cine más apegado al realismo ofrece numerosos ejemplos de personajes pertenecientes a lo que se considera "la otredad". Este trabajo se centra en la etapa que atraviesa desde 1999 a 2011 en el cine español, abordando el análisis de los caracteres de tres esferas diferentes de "otros": temáticas sociales como la inmigración, las identidades sexuales o de género no normativas y la delincuencia se desarrollan desde perspectivas individuales, cotidianas y concretas apoyando la tesis de Quintana (2008) en la que denomina "realismo tímido" esta forma de tratar lo social. Para el acercamiento y profundización en estos personajes olvidados y marginales se buscan las particularidades principales y las constantes a partir del análisis narrativo y el estudio de casos.

\begin{abstract}
:
Spanish social cinema chooses to emphasize narrative universes related to microhistory in order to show a society in evolution from the time of the political transition. The turn of the millennium presents a panorama that has many differences with previous stages, therefore the cinema more attached to realism offers numerous examples of characters belonging to what is considered "the otherness". This paper focuses on the period from 1999 to 2011 in Spanish cinema, analyzing the characters of three different spheres of "others": social issues such as immigration, non-normative sexual and gender identities and crime are developed from individual, daily and concrete perspectives, supporting Quintana's thesis (2008) in which he calls this way of dealing with social issues "shy realism". In order to approach these forgotten and marginal characters in greater depth, the main particularities and constants are sought through narrative analysis and case studies.
\end{abstract}

Palabras clave: Cine español; otredad; marginalidad; delincuencia; transidentidad; inmigración.

Keywords: Spanish cinema; otherness; marginality; crime; trans identities; immigration. 


\section{Introducción: cine social, personajes y espacios}

El cine de temática realista, con implicaciones sociales, políticas o documentales, se remonta a los inicios del cinematógrafo y se desarrolla durante todo el siglo XX, despuntando movimientos como el Cine-Ojo, el Cine Verité, el Neorrealismo italiano y el Free Cinema inglés, entre otros. Actualmente, este cine es denominado cine social (Pantoja Chaves, 2011, p. 407).

En España, las temáticas sociales se toparon con la dictadura y sus censores, de los que escaparon solo unos pocos directores y guionistas (Bardem, Berlanga, Azcona, Mihura, Saura, Querejeta...). El movimiento que aglutinó esa crítica social estaría ocupado por el Cine de la Disidencia en los años cincuenta y por el Nuevo Cine Español en los sesenta. Con la llegada de la democracia, las salas se vieron salpicadas de largometrajes de crítica política y social, con temáticas nuevas como la homosexualidad, la transidentidad y la delincuencia juvenil. Los gobiernos conservadores de Aznar y socialistas de José Luis R. Zapatero enmarcan una etapa repleta de situaciones sociales adversas o novedosas (como el paro o la llegada de inmigrantes) que se reflejarán en el cine. Jordi Costa define a los cineastas de la última década del siglo XX como representantes del Joven Cine Español (JCE), realizadores que muestran una visión de la sociedad volcada, sobre todo, hacia el individuo, con inquietudes como la inmigración, el paro, las drogas, la homosexualidad, los nuevos roles de género, etc. (Caparrós Lera \& de España, 2018, p. 190). Ángel Quintana (2008) denomina a este cine de "realismo tímido", pues donde más explícita aparece la crítica social es en los propios personajes y en los espacios que habitan, ya que las dimensiones colectivas y los elementos que atañen a la macrohistoria dan paso a puntos de vista mucho más reducidos y concretos, donde la problemática social se ciñe a un único personaje o un pequeño grupo.

\section{Objetivos y metodología}

La revisión de ciertos personajes, alejados de la épica y el sentido heroico, e incluso de la "normalidad" (entendida tanto desde la estadística como desde el 
etnocentrismo), dentro de la filmografía española del periodo 1999-2012 $^{1}$ es el objetivo principal de este trabajo. Podríamos considerar que temáticas sobre la inmigración, la identidad sexual no normativa y la delincuencia organizan un conjunto de personajes olvidados, que abonan el terreno para un realismo crítico y una sensibilidad social y humanista que permite hablar del "cine de la alteridad" (Gordillo, 2018) y que tiene como axioma la reflexión crítica sin llegar a la denuncia. Así, nos proponemos describir ciertos personajes protagonistas del cine de la alteridad y observar sus conexiones con otros personajes y con los espacios en los que desarrollan sus acciones. Con ello se podrá establecer una relación entre el cine social de este periodo y las temáticas relacionadas con la delincuencia, la transidentidad y la inmigración.

El diseño de la investigación se ubica en un paradigma constructivista y se apoya en el estudio de caso, combinado con el análisis narrativo del corpus de películas. Las obras seleccionadas para abordar la inmigración son Princesas (2005) y Amador (2010) de Fernando León de Aranoa. En el ámbito de la transidentidad se analizarán El calentito (2005) de Chus Gutiérrez y 20 centímetros (2005) de Ramón Salazar. Y, por último, para observar aspectos de la delincuencia se contemplan dos de las películas de Alberto Rodríguez: El traje (2002) y 7 vírgenes (2005). Se ha optado por escoger obras con representación suficiente y significativa de los tres colectivos tratados, siempre dentro del periodo estudiado (inicios del siglo XXI), sin que la fecha concreta de cada película sea un elemento sustancial.

Se considera que las seis obras son representativas del comportamiento social de la vida en España durante el periodo elegido, correspondiente a los aspectos de inmigración, transidentidad y delincuencia. El estudio de casos ha demostrado que "la muestra cualitativa permite obtener resultados generalizables para el universo, dentro de límites de representatividad socioestructural” (Mejía, 200o, p. 167).

Para realizar el análisis de las películas se tiene como referente metodologías de análisis narrativo de carácter estructuralista y posestructuralista, a partir de las que

\footnotetext{
1 Esta investigación forma parte del proyecto de $\mathrm{I}+\mathrm{D}+\mathrm{i}$ del Ministerio de Ciencia, Innovación y Universidades de España titulado "Desplazamientos, emergencias y nuevos sujetos sociales en el cine español (1996-2011)”.
} 
se genera una ficha de aplicación a cada uno de los personajes seleccionados de cada una de las seis películas escogidas.

La ficha de análisis abarcará tres fases diferentes. La primera recogerá los datos técnicos y semánticos de la obra (desde la ficha técnico-artística, la sinopsis y el tema principal, hasta el género y las temáticas tratadas); la segunda aborda aspectos sobre los personajes principales: datos del personaje como persona (apariencia física y carácter) y como rol (personaje activo/pasivo, influenciador, autónomo, tipo de protagonismo), comportamiento, acciones y relaciones con los espacios y con otros personajes. Y la última fijará su atención en el profílmico y en especial en la puesta en escena (iluminación, fotografía, montaje, banda sonora, etc.) además de los temas que se relacionan con el personaje. A partir de la aplicación de la ficha, los resultados se someten a una discusión y confrontación entre cada una de las dos películas elegidas para cada colectivo y se extraerán las conclusiones pertinentes.

\section{Corpus teórico y estudio de casos: inmigración, transidentidad y delincuencia}

\subsection{La inmigración en el cine español}

Los primeros inmigrantes como personajes protagonistas del cine hecho en España aparecen en 1990. Son el reflejo de una sociedad que comienza a recibirlos de forma sistemática en la década de los ochenta. La película pionera fue Las cartas de Alou (Montxo Armendáriz, 1990), a la que siguieron muchas otras, organizando un conjunto de filmes que puede englobarse en lo que ha venido denominándose de diversos modos: cine de la inmigración, outlandish cinema (Ponzanesi \& Merolla, 2005), o cine de la alteridad (Gordillo, 2018). En estos filmes se muestra una de las tendencias más marcadas del cine español de cambio de siglo: las temáticas relacionadas en poner voz y rostro a colectivos afectados por la globalización y por el recrudecimiento de las políticas sociales (Pohl \& Türschmann, 2007, p. 20 y Lobo, 2013, p. 4). El cine de la alteridad, que en España tuvo un desarrollo importante a partir de 1996, se basa en diferentes estrategias narrativas entre las que destaca la construcción del inmigrante como personaje protagonista (individual o coral), con 
características multidimensionales, fuera del estereotipo y a partir del uso coherente de una focalización interna dominante (Gordillo, 2018, p. 33). Por otro lado, es innegable que "la variedad de perspectivas que presentan estos filmes son un testimonio del profundo debate al respecto que vive la propia sociedad española" (Cavielles-Llamas 2008, p. 4).

Para el estudio del emigrante como personaje con una identidad no normalizada (son los "otros" frente al "nosotros" del español oriundo), vamos a centrar nuestro estudio en dos casos del mismo director: los filmes Princesas (2005) y Amador (2010), del director español Fernando León de Aranoa.

Princesas es una película que bucea en la prostitución con una mirada alejada de los estereotipos. Refleja la vida de un grupo de prostitutas en un momento en el que España recibe inmigrantes, por lo que existe un enfrentamiento entre las españolas y las que vienen de fuera. Fernando León elige a Candela Peña para interpretar a Cayetana, (Caye), una chica de Madrid, con una familia de clase media. Caye y otras colegas se agrupan en la peluquería de Gloria (Llum Barrera) para charlar y criticar a las prostitutas que vienen de Latinoamérica y les quitan clientes.

Una de ellas, Zulema, vive en el mismo edificio que Caye y poco a poco se van acercando. Zulema -interpretada por Micaela Nevárez- es dominicana y manda dinero a su madre, quien le cuida a su hijo de 5 años. Sueña con poder traer a su niño, cuando las cosas mejoren.

En Amador Marcela -interpretada por Magali Solier- es una inmigrante andina casada con Nelson. Viven en España y subsisten humildemente. Nelson coordina a un grupo de inmigrantes de diferentes orígenes para recoger (o robar) flores de desechos, clasificarlas y venderlas. Mientras, las guarda en su propio frigorífico. Cuando se estropea el electrodoméstico Marcela busca una ocupación extra y es contratada para cuidar durante un mes a un anciano (el Amador del título, interpretado por Celso Bugallo) postrado en una cama.

Las dos películas de Fernando León están protagonizadas por personajes con un territorio compartido: ambas son mujeres inmigrantes procedentes de Latinoamérica, viven en entornos urbanos, tienen una situación no regularizada, 
están en escenarios económicos precarios, son jóvenes trabajadoras y anhelan volver a su país. Sin embargo, las dos películas son muy distintas en lo tocante a su manera de concebir la otredad. En Princesas el tema de la inmigración aparece en primer plano, con un tratamiento claramente subrayado, intentando que Zulema represente a muchas de las mujeres que llegan a España dejando sus hijos en sus países de origen para intentar buscar una situación económica que les permita o bien regresar, o bien instalarse legalmente y traer a sus familias. Sin embargo, Amador refleja en un plano mucho más relegado el asunto de las migraciones y se centra en el dilema moral de Marcela, un personaje presionado por una dura situación económica. Como establece Casimiro Torreiro (2010), Amador es "mucho menos una película sobre inmigración que un poderoso, ejemplar retrato de mujer en el atolladero". Es interesante esta perspectiva porque de ese modo "el otro" ese hace mucho más cercano, se convierte en un personaje más humanizado y menos estereotipado a partir de una concepción etnocentrista de la narrativa. Zulema y Marcela, por tanto, son dos mujeres que representan la misma realidad contemplada desde ángulos diferentes, enriqueciendo los matices que el cine de la alteridad aporta dentro del panorama del cine español.

A partir de la implementación de la ficha de análisis expuesta en la metodología observamos los principales rasgos de ambos personajes:

\subsubsection{Datos del personaje}

El personaje de Zulema -una de las princesas del título- es joven, guapa, alta, delgada, mulata, llamativa y atractiva. Físicamente posee el exotismo que se achaca de forma racista al inmigrante de origen caribeño, como bien se dice en el filme (un personaje, en un momento de la película, expresa que las prostitutas extranjeras quitan clientes a las españolas porque son "más exóticas y más baratas”). Esta manera de ver la inmigración conecta con uno de los tópicos relacionados con el fenómeno: la amenaza del otro. Lo que se denomina "el problema de la inmigración” es "una construcción ideológica basada no en realidades o hechos sino en pasiones (reacciones por tanto irracionales) como el miedo" (Todorov, 2008 y Lobo, 2013, párr. 12). Este miedo convierte al inmigrante en una de estas posibilidades: un individuo potencialmente peligroso; una competencia en el plano laboral o 
económico; o un individuo étnicamente diferenciado e inasimilable (Lobo, 2013, párr. 13). De este modo, tanto Zulema como Marcela resultan ser un peligro por ofrecer sus servicios laborales a menores precios. En cambio, solo Zulema resulta étnicamente diferente, por sus rasgos propios de mulata.

En cambio, Marcela es una mujer casi invisible: físicamente su posible exotismo de rasgos andinos está escondido tras una manera de vestir, de andar y de moverse opuesta a Zulema. Es discreta, poco coqueta, tradicional y silenciosa. Su invisibilidad llega desde el título (donde no aparece) de una película que, sin embargo, protagoniza de forma rotunda. De todos modos, el nombre del título-Amador- posee una carga simbólica que va más allá del anciano que debe cuidar Marcela. Las conversaciones que tiene con él y la forma de mirar la vida de ese personaje que está en los últimos días de su existencia, hacen que Marcela se impregne de un espíritu de libertad y de conciencia sobre el ser que está en su vientre, del que no ha contado nada a nadie. Pero más allá de los pocos días que comparte con el anciano, la mujer no se relaciona con españoles de tú a tú como sí lo hace Zulema. Marcela pasa gran parte de la película sola, agobiada por su problema moral cuando el anciano muere y ella decide no comunicarlo ni a la familia ni a nadie para poder cobrar todo el mes de trabajo.

Ambos personajes son protagonistas, activos y de carácter tranquilo. Marcela parece un personaje conservador, pero al final de la película la observamos tomar decisiones valientes con consecuencias importantes. Al igual que Zulema, que en el desenlace resuelve la venganza y el regreso a su país, con la ayuda de Caye. Ambas demuestran una fuerza y un valor propios de heroínas activas e influenciadoras.

\subsubsection{Relaciones con otros personajes}

Otros contrastes entre ambas mujeres se desarrollan en el terreno de las relaciones con otros personajes del relato que protagonizan. Princesas es ante todo una película sobre el afecto entre dos mujeres muy diferentes: Zulema afianza su amistad con Caye a partir de un comienzo hostil marcado por la competitividad. Entre las dos mujeres se teje una amistad llena de matices de sororidad, a pesar de lo diferentes que son entre sí. Zulema se relaciona en la distancia con su hijo y su madre, entre 
nostalgias, mentiras y dolor. También con el funcionario que la engaña y extorsiona y que termina agrediéndola. Por ello, la amistad con Caye es un bálsamo que llega en un momento vital complicado y que se convierte en su tabla de salvación.

En cambio, Marcela apenas se relaciona con los españoles. La mujer que la contrata tiene una breve conversación con ella y lacónicos diálogos telefónicos preguntando por su padre. Amador al inicio prácticamente no le habla, y cuando empiezan a tener algunas conversaciones en las que él va contando su peculiar modo de ver la vida, muere de forma inesperada. Marcela pasa la mayor parte del día en silencio, sin compartir sus intensas dudas y preocupaciones por su futuro y el de su hijo. Sin embargo, aquellas pocas conversaciones con Amador, como se señaló más arriba, van a dejar una huella importante para la toma de decisiones y la nueva manera de enfocar su vida.

Así pues, en ambas películas el inmigrante encuentra una especie de mentor en la figura del español: Caye, con su amistad sincera, su ayuda y el gesto generoso final hacia Zulema en Princesas y Amador, desde su reposo huraño y soñador que abre perspectivas de libertad en la mente y en los planes de Marcela.

\subsubsection{Relaciones con el espacio}

Otro punto en el que Zulema y Marcela difieren son los espacios. El territorio de Zulema es la calle. De hecho, al no poder pagar el alquiler de un piso completo para ella, comparte con otra familia la vivienda a partir de turnos de 12 horas. Pasea, charla con Caye en las cafeterías, y apenas se le ve dentro de su casa pues ejerce su trabajo de madrugada y solo puede estar en el modesto piso algunas horas del día para dormir.

En cambio, Marcela está siempre en casa. En la de Amador, que se convierte en su segunda casa (una casa prestada que ella atiende), donde está casi como de visita, con un teléfono que cuando suena parece que la espía y un timbre que siempre la sorprende en momentos poco oportunos. La casa en la que vive con Nelson le resulta mucho más ajena (su marido en numerosas ocasiones conduce desde allí su negocio, usándola como almacén de flores, oficina, sala de reuniones para los encargos, etc.), por lo que muchas veces, al llegar a casa, Marcela encuentra a otros inmigrantes allí. 
Para Lobo, en Princesas hay una especie de linde simbólico al que llama "frontera de cristal”. El espacio que separa a las españolas de las inmigrantes invasoras está enmarcado por la cristalera de la peluquería donde se reúnen las oriundas y desde la que se puede observar la plaza donde ejercen las prostitutas extranjeras. Ese cristal compartimenta el dentro y el fuera,

el 'aquí' de las prostitutas autóctonas y un allí de las inmigrantes, las «otras», (...) como queriendo subrayar su calidad de trinchera, de refugio, de defensa contra la amenaza exterior y también de punto de observación, suerte de garita desde donde controlar los movimientos del exterior (Lobo, 2013, párr. 43).

En Princesas no hay castillos ni reinos. Tampoco príncipes azules... una peluquería de barrio junto a calles y plazas de distritos humildes. Son zonas asociadas a la prostitución, pobreza, enfermedades, malos tratos, abusos, sordidez, mediocridad y tristeza. En Amador la principal vivienda es una casa ajena, invisibilizando un poco más la personalidad, los gustos y las particularidades de Marcela. Para llegar a ella desde su casa en los suburbios Marcela debe atravesar zonas de descampados y tomar varios autobuses públicos. Una casa donde huele a muerte pero que Marcela llena de flores para intentar paliar el olor. Los espacios sirven para mostrar la personalidad, la vida y la forma de considerar estas manifestaciones de otredad en el cine y en la sociedad española.

\subsection{La identidad trans en el cine español}

La identidad trans ha sido escasamente representada a lo largo de la historia del cine español: son contados los casos en los que se han mostrado a personajes trans como protagonistas o secundarios. Más frecuente ha sido la representación del travestismo, que ya durante la dictadura comenzaron a aparecer y proliferaron durante los 50 convirtiéndose en un elemento recurrente, sobre todo en la comedia, que acudía a estas representaciones mediante el planteamiento de situaciones de equívoco al servicio del humor (Melero, 2017, p. 207-209).

El travestismo se posiciona como la antesala a la transidentidad en un panorama sociopolítico donde no existían los términos actuales y plantear una reasignación física aún era algo prácticamente inimaginable. La evolución de los conceptos y del 
lenguaje utilizado para hacer referencia a la identidad trans ha sido amplia. Ya en los años 20, Magnus Hirschfeld comienza a sugerir esta cuestión identitaria mencionando la existencia de un "tercer género", apelando a "una variación natural de la sexualidad humana" (Platero, 2014, p. 93). Desde el término travesti hasta el uso más reciente de persona/identidad trans se han encontrado diversidad de propuestas terminológicas tratando de adaptar el lenguaje a la realidad a la que se hace referencia. Sin entrar a comentar esta amplia evolución sobre los conceptos y sus usos, abordados en textos como los de Stryker (2017), Halberstam (2018) o Platero (2014), sí vamos a concretar que a lo largo de esta investigación vamos a emplear "personas trans" y "transidentidad" para referirnos al colectivo y a los personajes representados.

Hasta los años 70 el colectivo trans no comenzó a tener presencia en España. Durante mucho tiempo se contextualizó dentro de las leyes y consideraciones relativas a la homosexualidad que englobaban la identidad de género, sexo y sexoafectiva. En realidad, "es a raíz de la despenalización de la homosexualidad cuando se puede comenzar a hablar de la regulación de cuestiones relativas a la transexualidad de forma independiente" (Belsué-Guillorme, 2012, p. 214). No fue hasta 2007 cuando entró en vigor la ley reguladora de la rectificación de la mención relativa al sexo de las personas que permite que las personas trans no deban someterse a una reasignación de sexo mediante cirugía. No obstante, sí obliga a aportar un informe médico que diagnostique disforia de género (Guasch \& Mas Grau, 2014, p. 8), por lo que se continúa patologizando a estas personas pese a la ley. Volviendo a las representaciones cinematográficas de la transidentidad, encontramos que no será hasta la llegada de la transición democrática cuando se comiencen a presentar personajes trans. Filmes como Cambio de sexo (Vicente Aranda, 1977) o El transexual (José Jara, 1977) son los primeros en plantear esta cuestión en la gran pantalla, algo que no había sido posible durante el régimen dictatorial debido a la censura que se ejerció sobre este medio, exceptuando el caso de Mi querida señorita (Jaime de Armiñán, 1972). La película dirigida por Vicente Aranda trató de abordar el tema con anterioridad, pero dado que estaba prohibido aludir al mismo en la gran pantalla, fue censurado y hubo que esperar a la muerte de 
Franco para poder producirla. Este filme transgredió, además de por su contenido, por el uso del lenguaje que se hizo durante su promoción, puesto que "se empleó adecuadamente la palabra transexual, algo inusual en la sociedad y los medios de aquel momento" (Vegas, 2019, p. 41).

Más adelante se abordó la prostitución de mujeres trans, tanto en el documental con Vestida de azul (Antonio Giménez-Rico, 1983) como en la ficción, con Perras Callejeras, (José Antonio de la Loma, 1985), donde, sin embargo, no es el eje central. Cabe destacar, como señala Asenjo (2020), que aunque se hallen otras representaciones donde las mujeres trans han luchado y logrado puestos de trabajo de prestigio y en contextos históricos más desfavorables, sobre todo a nivel internacional, "la prostitución y el espectáculo, además de los salones de belleza, han sido históricamente medios de subsistencia para las comunidades de mujeres trans" (p. 112). Ya avanzados los 80, Colomo y Almodóvar vuelven a plantear la cuestión en sus obras con los títulos La vida alegre (1987) y La ley del deseo (1987), respectivamente, dos hitos relevantes en cuanto a un nuevo enfoque y tratamiento de la identidad trans en el cine de nuestro país. Algo que no sucede en el filme posterior Las edades de Lulú (1990) del director Bigas Lunas, donde se reduce la representación del colectivo a objeto de deseo.

Ya adentrándonos en las fechas de esta investigación, aparecen nuevas propuestas de Pedro Almodóvar, el director que en más ocasiones ha representado la transidentidad en el cine español con sus películas Todo sobre mi madre (1999), La mala educación (2004) y La piel que habito (2011). Sin embargo, dado que su obra ha sido estudiada en múltiples ocasiones, no nos centraremos en ellas en esta ocasión, sino que analizaremos dos obras de 2005, cuya visibilidad y recorrido no han sido tan significativos de cara al gran público: El calentito, dirigida por Chus Gutiérrez, y 20 centímetros de Ramón Salazar.

En El calentito encontramos a Antonia, una mujer trans, interpretada por Nuria González, un personaje secundario, dueña de la discoteca que da nombre al filme. Por su parte, 20 centímetros está protagonizada por Marieta, encarnada por Mónica Cervera, una joven trans cuyo mayor deseo es poder someterse a la cirugía de reasignación. Ambos filmes incorporan la música como elemento vertebrador de la 
obra: por una parte, El calentito gira en torno a un grupo musical, sus actuaciones y ensayos tienen una gran presencia; por otro lado, Marieta sufre narcolepsia y en sus ensoñaciones se introducen números musicales de diversa índole que tienen relación con acontecimientos, preocupaciones o anhelos del personaje.

Ambos filmes son anteriores a la legislación vigente por lo que los términos que se utilizan difieren de los actuales. Antonia, aunque es una mujer trans en cuanto a la concepción contemporánea, es calificada de travesti en el filme, que se ambienta en los 80. En estas fechas solamente se consideraba trans a las personas que habían pasado por una reasignación física.

\subsubsection{Datos del personaje}

Antonia tiene alrededor de 40 años, es madre de Jorge, dueña de El calentito y apoyo fundamental de Las siux, el grupo punk que protagoniza el filme, compuesto por Leo, Carmen y Sara. El personaje suele llevar una peluca de tono cobrizo, con una larga melena. Usualmente vemos al personaje con vestidos y faldas, calzando tacones que estilizan su figura, con pendientes y maquillaje que afianzan su aspecto dentro de la normatividad femenina. Por otra parte, Marieta tiene en torno a 30 años, y luce pelo rizado a la altura de los hombros, aunque para trabajar utiliza extensiones y se lo alisa. También su indumentaria cambia dependiendo del momento, cuando está en casa suele tener un aspecto desaliñado, sin embargo, por las noches viste minifaldas y escotes llamativos. Físicamente, estos dos personajes no guardan grandes similitudes.

Respecto a la corporeidad en relación con lo trans, debemos señalar que Marieta aparece completamente desnuda en dos ocasiones. En primer lugar, cuando aún no ha pasado por la cirugía de reasignación, por lo que se muestra con naturalidad el cuerpo trans en el que el personaje aún tiene pene. Al final del filme se ve su cuerpo nuevamente, esta vez sin pene. Su aspecto físico varía una vez que se ha operado, no sólo en cuanto a su genitalidad, sino su vestimenta y su pelo, ahora Marieta es más elegante y lleva el pelo rubio y liso. En el caso de Antonia, no se muestra el cuerpo desnudo, aunque se habla sobre su genitalidad, sobre sus pechos y el deseo de operarse si no fuese peligroso. 
Marieta es enamoradiza, idealista y soñadora; Antonia es racional y algo temerosa. Ambas son mujeres alegres pese a las situaciones amargas que han debido enfrentar a lo largo de sus vidas. También son sinceras, directas y tienen claro lo que quieren y quiénes son, luchadoras y valientes.

Es frecuente la aparición de elementos médicos relacionados con la identidad: tanto la hormonación como la cirugía de reasignación poseen presencia en ambos filmes.

\subsubsection{Relaciones con otros personajes}

El apoyo firme de diferentes personajes es un aspecto crucial en las dos obras analizadas. Los dos personajes cuentan con amigos o conocidos que hacen el duro camino transidentitario algo más liviano mediante la aceptación, el acompañamiento y la comprensión. Marieta cuenta principalmente con Tomás, quién, con sus más y sus menos, es una figura imprescindible en su devenir. Antonia tiene a La Vero y a Sara, confidentes y alentadoras de la búsqueda de felicidad del personaje. Además, Antonia ejerce de madre del grupo, protegiendo, cuidando y también regañando cuando es preciso.

También encontramos relaciones tormentosas. Por una parte, Marieta se enamora de Raúl un joven repartidor con el que vive un idílico romance hasta que se alude a la reasignación por la que Marieta tanto lleva luchando. Él desea a Marieta tal y como es, con su pene de 20 centímetros y no cree que deba operarse para ser una mujer, pero ella no está dispuesta a mantener aquello que la incomoda. Por ello la relación se vuelve dificultosa y acaba rompiéndose.

Antonia tiene, por una parte, un problema relacional con su hijo en cuanto a que este continúa sin aceptar al completo su identidad. Jorge sigue aludiendo a su madre en masculino y llamándola papá, lo cual hace que la relación materno-filial se resista, no obstante, a lo largo del filme se da una evolución en este sentido. Por otro lado, algunos vecinos acosan, insultan y amenazan al personaje, llegando a aparecer en el local con una pistola la noche del 23-F. De igual modo que la relación con su hijo mejora, en este caso, Antonia consigue plantar cara a esta situación y tomar el control. 
Es frecuente encontrar conversaciones de estas mujeres con otros personajes del colectivo, hablando de miedos y deseos. De estas conversaciones destaca la escena en la que Marieta y La Frío -interpretada por Rossy de Palma- hablan sobre las consecuencias de la operación en cuanto a la sensibilidad genital. También la prostitución y la violencia en el sector tienen cabida en 20 centímetros, así como el abuso de poder y la intolerancia de la derecha conservadora en El calentito.

\subsubsection{Relaciones con el espacio}

Puede decirse que en ambas obras hay una importante presencia del espacio "seguro" para los personajes analizados. En relación a Antonia tenemos El calentito, la discoteca donde se encuentra habitualmente. Solo en una ocasión aparece su casa, humilde pero no precaria. El local lo regenta ella por lo que tiene un control de este, no obstante, es un ambiente donde por lo general frecuentan personas del colectivo LGBT $+\mathrm{u}$ otros grupos sociales vinculados a lo alternativo política, social y culturalmente.

Marieta vive en un piso compartido, un espacio pequeño en un edificio en el que habitan otras personas vinculadas al ambiente nocturno y de la calle. Es un espacio precario, donde se relacionan cualquier identidad fuera de norma. No obstante, la relación del personaje con exteriores al final del filme es mostrada de forma diferente: ella camina de día por la calle, bajo el sol resplandeciente con una fotografía mucho más luminosa que la que se observa a lo largo del metraje.

\subsection{La delincuencia en el cine español}

El cine español durante su historia ha reflejado un catálogo de delitos de toda índole, así como de las penas legales o sociales impuestas. Durante años la prostitución y la libertad sexual de la mujer estaría representada como un delito y una deshonra para el hombre, y así se vería en La aldea maldita (Florián Rey, 1929) o en Centinela alerta (Jean Grémillon \& Luis Buñuel, 1937). Este delito ha evolucionado hasta estar vinculado con la drogadicción, la inmigración y la homosexualidad en las películas actuales. Durante la dictadura de Franco el continuo éxodo rural hacia las ciudades convierte a las grandes urbes y a sus barrios bajos en un caldo de cultivo para el delito. Se verán producciones con grandes robos para huir de la miseria constante, 
pero también hay pequeños hurtos de delincuentes de poca monta para cumplir algún sueño inalcanzable, como en Los atracadores (Francisco Rovira-Beleta, 1961), Distrito quinto (Julio Coll, 1957), Camino cortado (Ignacio F. Iquino, 1955) o Los tramposos (Pedro Lazaga, 1959) (López Juan, 2008, p. 152).

Durante la transición española y la década de los ochenta será la época dorada del cine quinqui, en el que los protagonistas se identificaron con sus personajes incluso fuera de la pantalla... Jóvenes como Juan José Moreno Cuenca, “el vaquilla”, que se erige en la figura máxima del delincuente español con un enorme historial de robos y atracos y enganchado a la heroína. Finalmente se convierte en el portavoz de los motines realizados en la cárcel Modelo de Barcelona. Morirá a los 42 años, por cirrosis hepática como consecuencia de su adicción a la heroína.

La figura del delincuente se equipara a la de un joven sin expectativas que para huir de sus orígenes comete delitos, bien en grupo o de forma individual, que le aportarán protagonismo ante sus iguales para alimentar su ego y su lucha por la supervivencia. "El quinqui no tiene voz, a pesar de sus apariciones fílmicas, pues no es capaz de articular un discurso propio: es el mismo silenciamiento estructural del sujeto subalterno (dentro de la narrativa histórica capitalista)” (Castelló Segarra, 2018, p. 126).

El cine quinqui se sitúa entre la realidad y la ficción, entre el barrio marginal y la sociedad de consumo, es un cine basado en las vivencias de los "héroes delincuentes" y su espectacularización. En este territorio destacan películas como Perros callejeros (José Antonio de la Loma, 1977), Navajeros (Eloy de la Iglesia, 1980), Deprisa, deprisa (Carlos Saura, 1981), El Pico (Eloy de la Iglesia, 1983) o Yo, “el Vaquilla”(De la Loma, 1985). En ellas resalta la presencia del barrio (Carabanchel en Madrid y La Mina en Barcelona), la oralidad y las canciones (diálogos potentes y rumbas de Los Chichos o los Chunguitos) y los coches (Seat 124, 1430, Renault 12). En este tipo de cine

el dinero pierde su valor mercantil y es tan volátil como los propios sujetos. Sujeto nómada, por necesidad y por vocación, el quinqui no tiene ataduras, ni materiales ni sociales. El único vínculo es con la pandilla y la novia de turno, pero incluso este último 
está sujeto a los cambios territoriales y es más fugaz que el primero. (Imbert, 2015, p. 64)

A finales de siglo XX y comienzo del XXI, la delincuencia seguirá presente en las pantallas, pero no con tanto vigor y fuerza. El thriller policíaco como subgénero y la banda terrorista ETA como personaje coral o temática se mantendrán en algunas producciones, sin abandonar un nuevo cine quinqui, que estaría englobado en el llamado "Cine de los olvidados".

Para abordar el tema de los personajes que están al otro lado de la ley se analizarán las dos primeras películas en solitario del director sevillano Alberto Rodríguez, El Traje y 7 Vírgenes. La primera cuenta la historia del inmigrante guineano Patricio (Eugenio José Roca), que sobrevive trabajando en una ciudad como Sevilla, tan clasista y contradictoria. Todo cambiará en su vida cuando se encuentre con el buscavidas y ladronzuelo, Pan con Queso (Manuel Morón), en un albergue de la ciudad y éste le robe su dinero. Según palabras del propio director la "idea era unir a dos personas sin remite, que no figuran legalmente en ninguna parte, sin derechos, y que sobreviven pícaramente en una ciudad que les es totalmente ajena” (Reviriego, 2002). En 7 vírgenes, Tano (Juan José Ballesta) que vive en un reformatorio, obtiene un permiso de 48 horas para asistir a la boda de su hermano. Ese fin de semana se reencuentra con su colega Richi (Jesús Carroza) con el que saboreará la libertad y revivirá pequeñas experiencias delictivas. El director en ambas obras afronta una realidad social desde los personajes masculinos, el humor y la tragedia. Una constante en las dos películas es la ausencia del protagonismo femenino pues solo aparecen mujeres como figuras esporádicas.

El Traje comienza siendo una película de inmigrantes, pero a raíz del hurto en el albergue para marginados, el honesto y correcto Patricio se verá abocado a participar con Pan con Queso en pequeños timos a viudas y cambios de billetes falsos. Con la secuencia de apertura del reformatorio, 7 vírgenes muestra un entorno delictivo que se verá incrementado cuando Tano se una a Richi, y comiencen a cometer pequeños hurtos en centros comerciales. Las dos obras no representan la delincuencia de la misma forma. En la primera, Pan con Queso estafa para poder sobrevivir y Patricio se ve obligado a seguirlo; sin embargo, en 7 vírgenes los protagonistas cometen robos 
y se pelean en las calles como expresión de libertad e inconformismo. En realidad, Tano y Richi no saben hacer otra cosa, no tienen expectativas para el futuro y se dejan llevar por una rutina marcada por la calle, el alcohol, las drogas y el aburrimiento. No son “quinquis”, solo jóvenes delincuentes ocasionales.

Ambos son filmes tiernos y duros a la vez. La temática es trágicamente dolorosa pero sus protagonistas resultan frágiles y sentimentales: al final la amistad sale a luz -en el caso de El traje- y también el vacío existencial en Tano al terminar 7 vírgenes. La delincuencia es un envoltorio para narrar historias personales.

\subsubsection{Datos del personaje}

El personaje de Pan con Queso es una persona madura, de pequeña estatura, pelo moreno y siempre bien peinado. Cuida su imagen rancia de timador, viste en traje de chaqueta para sus fechorías. Representa a un vividor sin escrúpulos que no tiene reparos en estafar a señoras mayores que se acaban de quedar viudas o colocar un billete falso en una tienda de barrio, e incluso le roba a un inmigrante (Patricio) el único dinero que tenía en su macuto mientras dormía. El personaje genera cierta repulsión, no se empatiza con él.

Tano es un joven menor de edad, moreno, con un corte de pelo de media melena, mirada profunda, de estatura media y complexión atlética. Viste camiseta, pantalón de chándal, y le gusta salir con su amigo Richi. No se sabe por qué delito está encerrado en el reformatorio, pero se muestra a un chico en momentos violento, pero normalmente pausado y reflexivo. Todo lo contrario de Richi, impulsivo y con incontinencia verbal. Cuando se unen forman un cóctel explosivo.

El traje tiene como protagonista a Patricio, un inmigrante negro, que solo se viste con el traje de chaqueta que le regaló casualmente un jugador de baloncesto a cambio de un favor. Pan con Queso es activo y manipulador, actúa como coprotagonista y es el contrapunto de Patricio.

En 7 vírgenes la historia se narra a través de Tano el protagonista principal, pero muy bien arropado de Richi, el personaje coprotagonista, quien, hasta su fatídica muerte final, será la única persona que soporta la angustia vital del primero. Alberto Rodríguez no intenta ahondar en las razones por las que cruzan la línea de la ley, 
solo quiere mostrar la visión de los personajes desde el momento en el que empieza a desarrollarse la acción.

\subsubsection{Relaciones con otros personajes}

La amistad que surge al final de El traje resulta forzada pues Pan con Queso no tiene amigos. El carácter del timador no permite las relaciones verdaderas, no se fía de nadie, pero a lo largo del filme tendrá que capitular en favor de Patricio. Es una amistad de una persona honesta, el inmigrante, con otra que aparentemente no conoce ningún límite a la hora del engaño y hacerse con el bien ajeno.

En 7 vírgenes la amistad marca la relación desde la infancia de los protagonistas, Tano y Richi. La falta de una figura paterna y de un futuro esperanzador une a estos dos personajes. Tano tiene a Patri (Alba Rodríguez) una novia que no le comprende, y a su hermano mayor Santacana (Vicente Romero) a quien considera un perdedor por seguir una rutinaria vida mediocre; todos se quieren, pero esas relaciones no llevan a Tano a ninguna parte. El último plano de la película es una declaración de intenciones, la imagen de Juanjo Ballesta congelada nos remite a Truffaut y su obra Los 4oo golpes (Les quatre cents coups, 1959), una auténtica carrera hacia la libertad (Heredero, 2005).

\subsubsection{Relaciones con el espacio}

La ciudad de Sevilla es un personaje más en la filmografía de Alberto Rodríguez. Los barrios marginales del extrarradio, así como los antiguos y descuidados del casco antiguo acogen las vidas disolutas de los protagonistas. En El traje, Pan con Queso habita en un antiguo hotel abandonado y en ruinas, en el casco histórico de Sevilla mientras que Patricio vivía en un barrio obrero de viviendas de protección oficial de cuatro plantas sin ascensor, justo antes de que la policía precintara el piso y tuviera que ir al albergue y, posteriormente, a vivir junto a Pan con Queso. La película transcurre entre los recovecos de las estrechas calles del centro y las avenidas de la ciudad.

En 7 vírgenes Tano y Richi "recorren las calles de una barriada obrera y marginal en una ciudad andaluza. Se reúnen para divertirse, emborracharse, trapichear con lo robado, realizar pequeños hurtos callejeros o participar en violentas vendettas con 
la banda rival" (Heredero, 2005). Los centros comerciales se convierten en un lugar idóneo para salir de la rutina y poder cometer sus fechorías.

El traje muestra la ciudad a pie, los protagonistas no tienen vehículo propio y deambulan por las calles buscando la próxima víctima. Richi junto a Tano surcan el barrio de grandes bloques de pisos y plazuelas llenas de jóvenes fumando y bebiendo. El ciclomotor trucado es el vehículo estrella para las pandillas de barrio, junto al coche tuneado de segunda o tercera mano. El barrio arropa y estimula, es la base de operaciones de estos jóvenes que ansían conseguir algo más que lo material.

\section{Conclusiones}

Tomando como punto de partida que algunos de los “otros" en el cine español del periodo 1999-2011 son los delincuentes (habituales personajes en el cine español desde el franquismo), las personas trans (que empiezan a aparecer en la época de la transición) y los inmigrantes (a partir de la década de los 90), se buscaron seis películas del periodo con objeto de establecer un corpus para el estudio de casos. La presencia de estos personajes en las películas de la muestra va mucho más allá de presentarlos como meros elementos de la puesta en escena (componentes del ambiente) o de aparecer como secundarios, pues se encuentran ya numerosas películas con estos personajes como protagonistas, activos e incluso influenciadores y modificadores.

Princesas y Amador otorgan un protagonismo importante a mujeres inmigrantes de América Latina que trabajan en España buscando un futuro de estabilidad económica. Son películas que se insertan en un cine social de estética intimista y un tono a veces poético y otras delicadamente tierno, donde se muestran historias que incluyen estas miradas detenidas en problemáticas muy presentes en la inmigración.

Por otro lado, tanto en $E l$ calentito como en 20 centímetros se ofrecen representaciones positivas de las personas trans, aunque todavía se encuentran territorios comunes -como la preocupación por lo físico- o espacios estereotipados, como el mundo de la noche o la prostitución. En los casos estudiados encontramos mujeres adultas, con vidas muy diferentes y desarrollos individuales diferenciados 
tanto por sus trayectorias como por sus formas de ver la vida, ofreciendo la heterogeneidad que la realidad misma ofrece.

En cuanto a los personajes del otro lado de la ley, las obras escogidas también reflejan puntos de partida muy distintos: en El traje encontramos la delincuencia como un modo de supervivencia y en el caso de Pan con queso, desde una posición de madurez. Frente a ella, en 7 vírgenes, son dos jóvenes los que ejercen la delincuencia como expresión de inconformismo, de ausencia de futuro y de ansias de libertad.

En todas las películas analizadas dentro de las tres temáticas los personajes están fuertemente relacionados con los espacios, que actúan de forma simbólica, organizando características de los matices que adornan a los personajes.

Y, por otro lado, es curioso que las seis películas tengan un elemento temático común que recorre a todos los personajes considerados como "otros": la relación de amistad profunda y apoyo constante con personajes del otro lado ("nosotros”).

Así pues, podemos considerar que más que crítica social de un determinado colectivo, es la problemática humana, individual y cotidiana, con una mirada entre poética y tierna la que más abunda en el cine social de este periodo. Es la confirmación de la existencia de un realismo tímido (Quintana, 2008) o minimalista donde los elementos de la microhistoria -que desarrollan dimensiones personalizadas de los temas sociales- se superponen a problemáticas que afectan al campo de la macrohistoria.

\section{Referencias bibliográficas}

Asenjo, D. (2020). Las tres edades y la violencia transfóbica en representaciones fílmicas occidentales. En F. A. Zurian, M. I. Menéndez y F. J. García-Ramos (Eds.), Edad y violencia en el cine. Diálogos entre estudios etarios, de género y filmicos. Palma: Edicions UIB.

Belsué-Guillorme, K. (2012). La legislación en torno a la transexualidad en España: Avances, debilidades y paradojas. Feminismo/s, 19, 211. Recuperado de http://dx.doi.org/10.14198/fem.2012.19.12

Caparrós Lera, J. M. \& De España, R. (2018). Historia del cine español. Madrid: $\mathrm{T} \& \mathrm{~B}$. 
Castelló Segarra, J. (2018). Cine quinqui. La pobreza como espectáculo de masas. Filmhistoria 28, (1-2), 113-128. Recuperado de https://revistes.ub.edu/index.php/filmhistoria/article/view/28319/29057

Cavielles-Llamas, I. (2008). De Otros a Nosotros: El Cine Español sobre Inmigración y su Camino hacia una Visión Pluricultural de España (19902007) (tesis inédita). University of Massachusetts. Recuperado de https://scholarworks.umass.edu/theses/246

Gordillo, I. (2018). La construcción de la alteridad. Cine e inmigración en la era socialista, en Área Abierta, 19 (1), 29-41. Recuperado de http://dx.doi.org/10.5209/ARAB.60731

Guasch, O. \& Mas Grau, J. (2014). La construcción médico-social de la transexualidad en España (1970-2014). Gazeta de Antropología, 3 (30), artículo 06. Recuperado de https://digibug.ugr.es/handle/10481/33813

Halberstam, J. (2018). Trans*. Una guía rápida y peculiar de la variabilidad de género. Egales: Barcelona/Madrid.

Heredero, C. (13 octubre, 2005). 7 vírgenes. El Cultural. Recuperado de https://elcultural.com/7-virgenes

Imbert, G. (2015). Cine quinqui e imaginarios sociales. Cuerpo e identidades de género. Área Abierta, 15, (3), pp. 57-67. Recuperado de https://doi.org/10.5209/rev_ARAB.2015.v15.n3.48937

Lobo, O. (2013). Princesas de Fernando León de Aranoa (2005) o la invención cinematográfica de un espacio hospitalario. Ilcea, 18. Recuperado de https://doi.org/10.4000/ilcea.2143

López Juan, A. (2008). El cine español como fuente documental para el estudio de los barrios marginales. Investigaciones Geográficas, 47, pp. 139-157. Recuperado de http://www.cervantesvirtual.com/obra/el-cine-espanolcomo-fuente-documental-para-el-estudio-de-los-barrios-marginales/

Mejía, J. (2000). El muestreo en la investigación cualitativa. Investigaciones Sociales, año IV, $\mathrm{n}^{\mathrm{0}}$ 5, pp. 165-180. Recuperado de http://sisbib.unmsm.edu.pe/bibvirtualdata/publicaciones/inv_sociales/ n5_2000/ao8.pdf

Melero, A. (2017). Violetas de España: gays y lesbianas en el cine de Franco. Madrid: Notorious Ediciones.

Pantoja Chaves, A. (2011). El cine social español de los años noventa. Fernando León de Aranoa como referente. En G. Capellán de Miguel, R. Fandiño y J. Pérez Serrano (Eds.), Historia Social, Movimientos Sociales y Ciudadanía (pp. 407428). Logroño: Instituto de Estudios Riojanos.

Pérez Morán, E. \& Sánchez Noriega, J. L. (2020). Panorámica: entre las nuevas pantallas y la polifonía audiovisual. En J. L. Sánchez Noriega (ed.), Cine español en la era digital: emergencias y encrucijadas (pp. 31-71). Barcelona: Laertes. 
Platero, R.L. (2014). Tran*exualidades. Acompañamiento, factores de salud y recursos educativos. Barcelona: Edicions Belaterra.

Pohl B. \& Türschmann J. (coord.) (2007). Miradas glocales: cine español en el cambio de milenio. Madrid: Iberoamericana-Vervuert.

Ponzanesi, S. \& Merolla D. ed. (2005). Migrant Cartographies: New Cultural and Literary Spaces in Postcolonial Europe. Oxford: Lexington Books

Quintana, A. (2008). Fernando León de Aranoa: Princesas (2005) y el realismo tímido en el cine español. En P. Feenstra y H. Hermans (Eds.) Miradas sobre pasado y presente en el cine español (1999-2005). (pp. 251-264) Amsterdam: Foro Hispánico.

Reviriego, C. (2002). Escribí El traje para eliminar mis prejuicios. El Mundo 31 de octubre. Recuperado de http://ibermediadigital.com/ibermediatelevision/entrevistas/escribi-el-traje-para-eliminar-mis-prejuicios/

Seger, L. (1987). Cómo convertir un buen guion en un guion excelente. Madrid: Ediciones Rialp.

Stryker, S. (2017). Historia de lo trans: Las raíces de la revolución de hoy. Madrid: Continta Me Tienes.

Todorov, T. (2008): El miedo a los bárbaros. Más allá del choque de civilizaciones, Barcelona: Galaxia Gutemberg.

Torreiro, C. (2005). El futuro y sus nostalgias. El País, 2 de septiembre. Recuperado de

http://www.cat.elpais.com/diario/2005/o9/02/cine/1125612019_850215.h $\underline{\mathrm{tml}}$

Vegas, V. (2019). Vestidas de azul. Análisis social y cinematográfico de la mujer transexual en los años de la transición española. Madrid: Dos Bigotes. 